\title{
Who Are the Teenagers of Today? Collective Imaginary of Brazilian Teachers
}

\author{
Miriam Tachibana, Aline Vilarinho Montezi, Tomíris Forner Barcelos, André Sirota, and Tânia Aiello \\ Vaisberg
}

\begin{abstract}
This research aims at investigating the collective imaginary of high school teachers regarding teenagers nowadays. It is based on the perspective that the school environment plays an important role in the process of emotion growth, and that this environment is highly affected by the teachers' behavior. As an empirical psychoanalytical study, this investigation is composed of individual interviews with five teachers using the Drawing-Story with Theme procedure as a dialogical mediating resource. Transferential narratives were then written based on the clinical encounter and considered psychoanalytically, alongside the drawing-stories, allowing the perception of two affective-emotional fields, "naturally alienated" and "defensively alienated". It is our understanding that these two fields might guide teachers to different conducts in regards to their young students, ranging from an equally alienated behavior in the classroom to attempts at closing the distance between them.
\end{abstract}

Index Terms - Teacher, adolescence, collective imaginary, $\mathrm{D}$. W. Winnicott, qualitative research.

\section{INTRODUCTION}

Investigation of current scientific literature shows us an expressive number of works on different social problems involving young people, such as drug and alcohol abuse [1], [2], early pregnancy [2], [3] and disturbing cases of self-aggression and suicide in this stage of development [4], [5].

If on one hand we consider these studies valuable, since they aim at producing scientific knowledge that favors the entrance of the young into adulthood, on the other we must worry about how many empirical studies treat adolescence as a "risk factor", in the epidemiological sense: a situation that increases the changes of disease development. We are concerned about an exaggeration that might encourage discrimination against teenagers.

Indeed, in a previously realized study in our $\mathrm{CNPq}$ research group, "Psychopathology, Psychoanalysis and Society", based at University of São Paulo, with brazilians high-school students, we noted that they are used to supporting a paranoid imagination in relation to the experience of sexuality, as if it were something forbidden and worthy of punishment, what may be closely related to prejudiced way in which the society faces the teenagers sexuality. [6].

It is our understanding, based on [7], [8], that the

Manuscript received November 10, 2013; revised January 22, 2013.

Miriam Tachibana, Aline Vilarinho Montezi, Tomíris Forner Barcelos, André Sirota, and Tânia Aiello Vaisberg are with Universidade de São Paulo, Brazil (e-mail: mirita@uol.com.br, alinemontezi@hotmail.com, tomirisfb@hotmail.com, a.sirota@orange.fr, aiello.vaisberg@gmail.com). emotional growth of a human being is anchored in his or her environment so that one of the ways for us to be able to face all these social problems involving teenagers is to generate scientific knowledge about the environment they live in.

This study is focused, therefore, in what high school teachers have to say about their teenage students, given that the teachers play an essential part in this environment, even though they are not responsible for it [9], [10].

\section{MethodolOGY}

In our research group, we develop studies on prejudiced and discriminatory conduct that generates social anguish, based on [8]-[11]. We use the term "collective imaginary" to refer to symbolic manifestations, a group of ideas, emotions, beliefs and images that a set collective produces in relation to a phenomenon [12]. So, in this study, we investigate the collective imaginary of teachers regarding teenagers, aiming at understanding the unconscious affective-emotional layer from which it emerges.

We understand that, through this study, it would be possible to produce scientific knowledge that could favor two social groups: 1) the group of teachers who deal daily with the young students; 2) the group of teenagers who are emotionally supported by their teachers and who benefit indirectly from interventions that are realized with them. For this research, we contacted a private school in the upstate of São Paulo.

We conducted individual interviews with five teachers using the approach called "individual interview as an approach to the collective personality" [13]. It is a specific type of interview, articulated around the use of dialogical mediating resources, clinical approaches based on Winnicott's therapeutic consultations [14]. In his therapeutic consultations, the British psychoanalyst used to use the Squiggle Game, through which he and his patient used to do together random scribbles, on a sheet of paper, which could form a drawing. By means of this playful fits, he believed that the emotional communication of their patients, who could, in this way, approach distressing issues by a relatively relaxed mode.

In this study with the same aim at facilitating emotional communication, we used the Drawing-Story with Theme procedure [15], asking the participants to draw "a teenager of present days", and then to create a story about the picture they drew.

After each interview we elaborated transferential narratives, which are a special form of registry, since the researcher relates not only what the participants said and did, but also his free associations and feelings that emerged from the clinical encounter [16], [17]. It is a methodological 
strategy effectively used in several studies about collective imaginaries by authors such as [9], [18], [19] and others and that is tuned to the psychoanalytic method, which really emphasizes the personality of the researcher, that is, their counter transference feelings in the knowledge construction.

All registries, constituted by the five drawing-stories of the teachers and by the five transference narratives that the researchers wrote from the experienced encounters, were psychoanalytically considered by the members of the study group following the procedure recommendations in [20], [21], which are rigorously based on the constitutive steps of the psychoanalytical method. Thus, making use of the main psychoanalytic techniques, that is, the free association and the fluctuating attention, the research team was impressed by the clinical material aiming at the production of the interpretative fields' emotional-affective sense, that we have understood as the logical-emotional determinants that produce the meanings of conducts adopted by the group of teachers.

We produced interpretatively two fields of affective-emotional meaning: "naturally alienated" and "defensively alienated".

\section{AfFective-Emotional MeAning FiELD}

Through psychoanalytical consideration of the clinical material, we noticed that all participants imagined contemporary youngsters as essentially alienated. Although all imaginative productions associated teenagers to a disconnection from reality, we were able to create two affective-emotional meaning fields, given that this juvenile alienation presented itself in connection with different beliefs.

That being said, in the imaginative productions connected to the "Naturally alienated" field, teenagers' alienation corresponded to a central and natural characteristic of adolescence. To illustrate this point, we present the Fig. 1 and a piece of the transference narrative that was written by the researcher who made this interview:

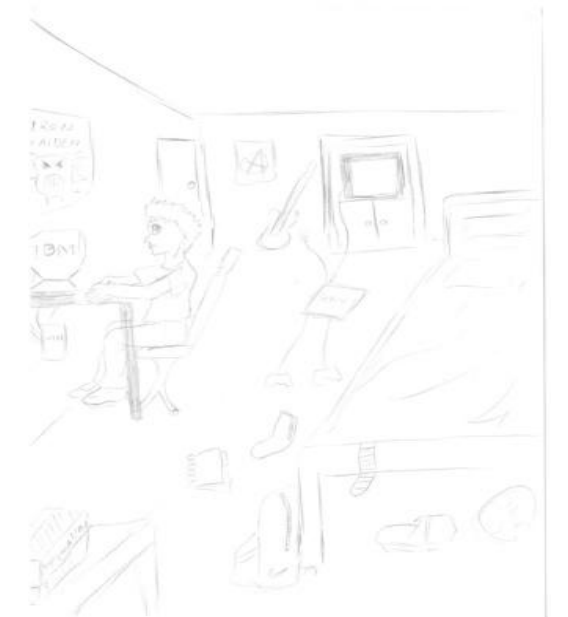

Fig. 1. No interaction.

"When I asked Marcos" to explain what he drawn, he said that the teenager in the picture represented the students he

\footnotetext{
${ }^{1}$ All names are fictitious as a way of preserving anonymity, according to Code of Ethics in Psychology.
}

had had contact with during his time as a teacher. He then added: 'I imagined him in a messy room, full of electronics, like a computer, MP4, electric guitar (that he doesn't play, but it's still there), and a ball under the bed, that he hardly uses... most of the time, he's secluded in his computer instead of interacting with people.",

On the other hand, imaginative productions from the "Defensively alienated" field associate youth alienation to social pressure involving parents' expectations and peer pressure. From that perspective, teenagers' retracted behavior would relate to an emotional suffering associated to the feeling of submission. We selected the Fig. 2 and a part of the narrative written by the researcher that made this interview:

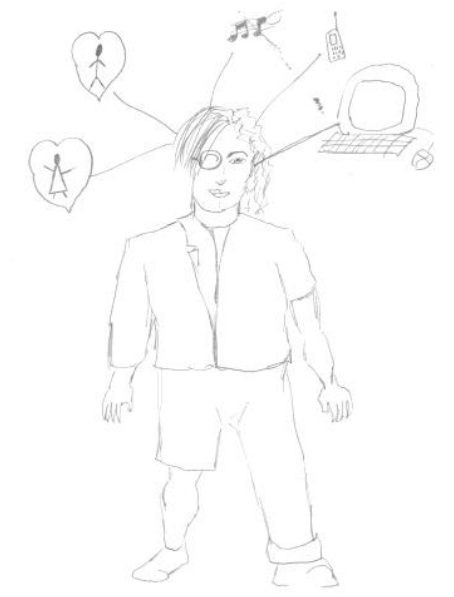

Fig. 2. Difficult period.

"After completing his drawing, Pablo said he had tried to represent a teenager picking up the 'pieces' to move on with his life. He said that the teenager is often kept from being who he would really like to be: 'How many artists have we not lost because they didn't have the chance to enjoy their talent, giving in to society, or even to their parents?' From this point, he started talking about his own teen years, often remarking that it was a difficult period, since he had to make important choices (about which carrier to follow, in which university to study...) without being truly prepared. He concludes by saying: 'The reason for a teenager to spend most of his time with his head in the clouds is out of necessity. ,",

\section{CONCLUSION}

Through this study we were able to notice that, in the imaginary of the studied collective, teenagers are seen as alienated individuals. For a part of this group, this alienation would be linked to their inability to relate to a rich reality (with sports, music, books), from which he would remain disconnected. For another part of the participants, alienated conduct would be associated to a defensive strategy teenagers use to face an impoverished world, that demands from them conformity to social expectations and submission above all to parental desires.

It becomes clear, in this way, that while in the first group of imaginative productions teachers' imaginary represents a teenager putting to waste the rich world in which they live, in the second group it represents the opposite, an environment that is putting to waste all 'the talent' teenagers have to offer, as highlighted by one of the participants. 
It is our understanding that this duplicity in the participants' collective imaginary may sustain very different professional conducts in regards to their teenage students. We may consider, for instance, that a teacher aligned to the "naturally alienated" field, meaning they would believe there's nothing they can do to remove their student from a state of self-closing, might assume an equally alienated posture in the classroom, not trying to attract teenagers to the school reality. It's as if the teacher, identifying themselves as part of the rich world the teenager is ignoring, felt unburdened by the task of entering the 'impoverished' universe inhabited by their students.

In the same way, it is possible to imagine a teacher deeply aligned to the "defensively alienated" field might sensibly adopt the opposite conduct and try to get closer to their teenage students without triggering a defensive response. In this case, it is as if the teacher felt responsible for making teenagers' reality richer so that they might relate to it in a non-submissive manner.

We come, then, to the conclusion that the investigation on the collective imaginary of teachers regarding their young students may provide us with means to reach a deeper understanding of their attitudes in the classroom, which might benefit not only a group of teachers but also the group of young people they share the school environment with.

\section{REFERENCES}

[1] I. Andretta and M. de S. Oliveira, "Motivational interviewing in adolescent drug users who had committed infractional acts," Psychology, Reflection and Review, vol. 24, no. 2, pp. 218-226, 2010.

[2] V. G. Caputo and I. A. Bordin, "Teenage pregnancy and frequent use of alcohol and drugs in a family context," Review of Public Health, vol. 42, no. 3, pp. 402-410, 2008.

[3] J. Pariz, C. F. Mengarda, and C. B. Frizzo, "The care and attention to teenager's pregnancy in the family, political spheres and in society: A literature review," Social Health, vol. 21, no. 3, pp. 623-636, 2012.

[4] L. da C. Araújo, K. F. L. Vieira, and M. da P. de L. Coutinho, "Suicidal ideation in adolescence: A psychosocial approach in the context of high school," Psico-USF, vol. 15, no. 1, pp. 47-57, 2010.

[5] F. S. Teixeira-Filho and C. A. Rondini, "Ideation and suicide attempts in adolescents with heterosexual and homoerotic sexual practices," Social Health, vol. 3, no. 21, pp. 651-667, 2012.

[6] M. L. da S. Pontes, T. F. Barcelos, M. Tachibana, and T. M. J. Aiello-Vaisberg, "Early pregnancy in the collective imaginary of teenagers," Psychology: Theory and Practice, vol. 12, pp. 85-96, 2010.

[7] D. W. Winnicott, "Primitive emotional development," Collected Papers: Through Pediatrics to Psycho-Analysis, pp. 269-285, Rio de Janeiro: Francisco Alves, 1945.

[8] J. Bleger, Psychology of Conduct, Porto Alegre: Medical Arts, 1963.

[9] K. P. Zia, "Water drop: The collective imaginary of inclusive educators about being a teacher in times of inclusion," PhD thesis, University of Campinas, Campinas, São Paulo, 2012.

[10] A. Sirota, "Why the violence?" Childhoods Psy., vol. 45, pp. 102-108, 2009.

[11] G. Politzer, Critique of the Foundations of Psychology: Psychology and Psychoanalysis, São Paulo: UNIMEP, 1928.

[12] M. C. L. Machado et al., "Psychoanalytic research of collective imaginary with the champ's theory," Fábio Herrmann, a Psychoanalytic Journey, pp. 311-324, São Carlos: publishing house Pedro e João editores, 2008.

[13] C. Ávila, M. Tachibana et al., "Where is the place of disabled students? The collective imaginary of teachers about inclusive education," Paidéia, vol. 18, pp. 155-164, 2008.
[14] D. W. Winnicott, Therapeutic Consultations in Child Psychiatry, Porto Alegre: Medical Arts, 1970.

[15] T. M. J. Aiello-Vaisberg, "Encounter with madness: Transitionality and psychopathology teaching," Habilitation thesis, Institute of Psychology, University of São Paulo, São Paulo, 1999.

[16] T. M. M. Granato et al., "Weaving clinical research with psychoanalytic narratives," Changings, vol. 12, no. 2, pp. 253-271, 2004.

[17] M. C. L. Machado, T. Ayouch et al., "Narratives transferénciels as presentation of clinical experience: A methodological proposal," Psychoanalysis, Philosophy and Art: Dialogues, pp. 39-52, Paris: L'Harmattan, 2009.

[18] M. Tachibana, "End of the world: The collective imaginary of the nursing staff about the interrupted pregnancy," PhD thesis, University of Campinas, Campinas, São Paulo, 2011.

[19] C. I. C. de M. Camps, "Being and doing in career choice: Differentiated service in Winnicott's clinic," PhD thesis, Institute of Psychology, University of São Paulo, São Paulo, 2009.

[20] F. Herrmann, Introduction to Champ's Theory, São Paulo: Psychology's House, 2001

[21] A. V. Montezi, K. P. Zia et al., "Collective Imaginary of teachers about contemporary teenagers," Psychology in Study, vol. 16, pp. 299-305, 2011

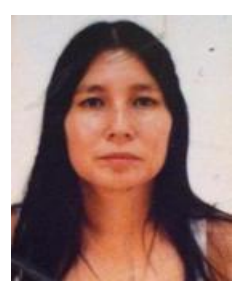

Miriam Tachibana is a post-doctoral student focusing in Clinical Psychology through the Institute of Psychology at the University of São Paulo, Brazil, and University of Paris X-Nanterre, France, with a FAPESP scholarship.

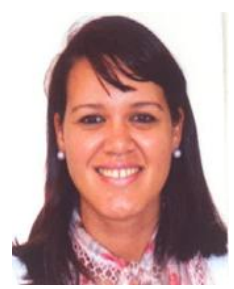

Aline Vilarinho Montezi is a doctoral student focusing in Clinical Psychology through the Institute of Psychology at the University of São Paulo, Brazil, with a CAPES scholarship.

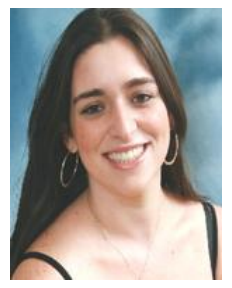

Tomíris Forner Barcelos is a master's degree program student focusing in Clinical Psychology through the Institute of Psychology at the University of São Paulo, Brazil, with a CAPES scholarship.

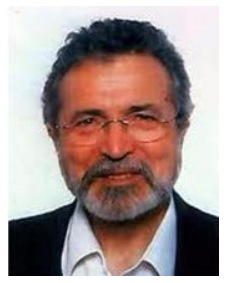

André Sirota has obtained his $\mathrm{PhD}$ dgree. $\mathrm{He}$ currently works as a professor and master and doctoral students' Tutor at University of Paris X - Nanterre, France.

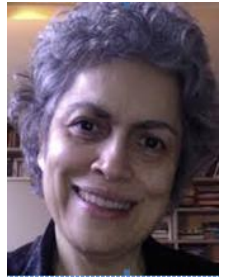

Tânia Maria Aiello Vaisberg has obtained her PhD dgree. She currently works as a professor and master and doctoral students' Tutor at the Institute of Psychology at the University of São Paulo, Brazil. 